\title{
The Role and Expression of Angiogenesis-Related miRNAs in Gastric Cancer
}

\author{
Martina Giuppi ${ }^{1}$, Anna La Salvia ${ }^{2}$ (D) Jessica Evangelista ${ }^{3}$ and Michele Ghidini ${ }^{4, *(D)}$ \\ 1 Faculty of Medicine, CEU San Pablo University, 28003 Madrid, Spain; mar.giuppi@ceindo.ceu.es \\ 2 Department of Oncology, University Hospital 12 de Octubre, 28041 Madrid, Spain; alasalvi@ucm.es \\ 3 Thoracic Surgery, Fondazione Policlinico Universitario A. Gemelli IRCCS, 00168 Rome, Italy; \\ evangelistajessica664@gmail.com \\ 4 Oncology Unit, Fondazione IRCCS Ca' Granda Ospedale Maggiore Policlinico, 20122 Milan, Italy \\ * Correspondence: michele.ghidini@policlinico.mi.it; Tel.: +39-02-5503-2660; Fax: +39-02-5503-2659
}

check for updates

Citation: Giuppi, M.; La Salvia, A.; Evangelista, J.; Ghidini, M. The Role and Expression of AngiogenesisRelated miRNAs in Gastric Cancer. Biology 2021, 10, 146. https:// doi.org/10.3390/biology10020146

Academic Editors: Alessio Biagioni and Fabio Staderini

Received: 30 December 2020

Accepted: 8 February 2021

Published: 12 February 2021

Publisher's Note: MDPI stays neutral with regard to jurisdictional claims in published maps and institutional affiliations.

Copyright: (C) 2021 by the authors. Licensee MDPI, Basel, Switzerland. This article is an open access article distributed under the terms and conditions of the Creative Commons Attribution (CC BY) license (https:/ / creativecommons.org/licenses/by/ $4.0 /)$.
Simple Summary: The aberrant expression of several micro RNAs (miRNAs) has been shown to be involved in neoplastic angiogenesis, which is a crucial mechanism in gastric cancer onset and progression. In this review, the possible prognostic and predictive roles of angiogenesis-related miRNAs as novel biomarkers of gastric cancer have been evaluated, but neither tissue nor circulating biomarkers have shown a predictive role for response to anti-angiogenic treatment. Nevertheless, we consider that in future studies, miRNAs should be evaluated as candidate biomarkers with prognostic and predictive features.

Abstract: Gastric cancer (GC) is the fifth most frequently diagnosed malignant tumor and the third highest cause of cancer mortality worldwide. For advanced GC, many novel drugs and combinations have been tested, but results are still disappointing, and the disease is incurable in the majority of cases. In this regard, it is critical to investigate the molecular mechanisms underlying GC development. Angiogenesis is one of the hallmarks of cancer with a fundamental role in GC growth and progression. Ramucirumab, a monoclonal antibody that binds to vascular endothelial growth factor-2 (VEGFR-2), is approved in the treatment of advanced and pretreated GC. However, no predictive biomarkers for ramucirumab have been identified so far. Micro RNAs (miRNAs) are a class of evolutionarily-conserved single-stranded non-coding RNAs that play an important role (via post-transcriptional regulation) in essentially all biologic processes, such as cell proliferation, differentiation, apoptosis, survival, invasion, and migration. In our review, we aimed to analyze the available data on the role of angiogenesis-related miRNAs in GC.

Keywords: Micro RNAs (miRNAs); gastric cancer; angiogenesis; VEGF; ramucirumab; biomarkers

\section{Introduction}

\subsection{Angiogenesis and Cancer}

Angiogenesis is a key player in the growth of cancer [1]. Tumor-associated neovasculature is important for delivering nourishment and oxygen to growing tumors. In addition, angiogenesis partakes in multiple aspects of tumor biology, including dissemination and metastasis processes [2], metabolic deregulation [3], and cancer stem cell maintenance $[4,5]$. Angiogenesis is a complex process by which new blood vessels are formed from pre-existing ones [6]. In normal conditions, the vasculature becomes largely quiescent. However, within tumors, an "angiogenic switch" is always activated, leading to the continuous generation of new vessels [7]. This "angiogenic switch" is governed by the upregulation of pro-angiogenic and downregulation of anti-angiogenic signals produced by tumor cells or the tumor microenvironment [8-10]. 


\subsection{Angiogenesis and Gastric Cancer}

The vascular endothelial growth factor (VEGF) family is a crucial mediator of angiogenesis [11]. The VEGF family consists of seven major subtypes, including VEGF-A, VEGF-B, VEGF-C, VEGF-D, VEGF-E, and placental grow factor 1 and 2 (PIGF-1 and PIGF2 , respectively) [12]. VEGF subtypes stimulate cellular responses by binding to tyrosine kinase receptors (VEGFR-1, -2,-3) on the cell surface. VEGF is produced by several cell types, such as fibroblasts, inflammatory cells and many tumoral cells, often in response to increasing tumor hypoxia via the hypoxia inducible factor- $1 \alpha$ (HIF- $1 \alpha$ ) pathway. Notably, the activation of VEGFR has a critical role in GC angiogenesis [13]. Approximately $50 \%$ of GCs express VEGF, and the overexpression of VEGF-A and VEGF-D in GC is associated with poor prognosis $[11,14]$. The hypoxia inducible factor (HIF) pathway is also involved in angiogenesis. HIF- 1 is a dimeric protein (HIF- $1 \alpha$, HIF- $1 \beta)$ complex that plays an important role in the response to low oxygen concentrations or hypoxia. HIF-1 is a crucial physiological regulator of homeostasis, vascularization, and anerobic metabolism, but in cancer, it allows for the survival and proliferation of cancerous cells due to its angiogenic properties. HIF-1 is responsible for the migration of mature endothelial cells towards a hypoxic environment via the regulation of VEGF transcription [15].

A third important pathway for angiogenesis and tumorigenesis involves the hepatocyte growth factor (HGF)/tyrosine-protein kinase MET (c-MET) signaling pathway. HGF is a pleiotropic cytokine that has been reported to prevent and attenuate disease progression by influencing multiple pathophysiological processes and promoting cell proliferation, survival, motility, scattering, differentiation, and morphogenesis [16,17]. c-MET is a receptor tyrosine kinase that binds with its ligand (HGF) and activates a wide range of different cellular signaling pathways, including those that are involved in proliferation, motility, migration and invasion [17]. When the tyrosines within the multifunctional docking site become phosphorylated, they recruit: (1) signaling effectors such as the adaptor proteins growth factor receptor-bound protein 2 (GRB2), src homology 2 domain-containing (SHC), v-crk sarcoma virus CT10 oncogene homolog (CRK) and CRK-like (CRKL); (2) effector molecules such as phosphoinositide 3-kinase PI3K, phospholipase $\mathrm{C} \gamma$ (PLC $\gamma)$, the protooncogene tyrosine-protein kinase SRC, and the src homology 2 domain-containing $5^{\prime}$ inositol phosphatase (SHIP-2); and (3) signal transducer and activator of transcription-3 (STAT-3) $[18,19]$.

The phosphatidylinositol 3-kinase (PI3K) signaling pathway regulates growth, survival, proliferation, and angiogenesis [20-22]. This pathway has two major positive and negative regulators, PI3K and phosphatase and tensin homolog (PTEN), respectively, which are two of the most frequently mutated proteins in human cancers that are involved in tumorigenesis. PTEN mainly regulates PI3K signaling by dephosphorylating the lipid signaling intermediate, phosphatidylinositol $(3,4,5)$-trisphosphate $\left(\mathrm{PIP}_{3}\right)$, but may have additional phosphate-independent activities and other functions in the nucleus. PTEN is a tumor suppressor gene that negatively regulates mammalian target of rapamycin (mTOR) complex 1 (mTORC1) activity, which activates the translation of proteins. The restoration of PTEN expression may block angiogenesis in GC by inactivating the PI3K/protein kinase B (AKT) pathway [23]. Additionally, several miRNAs have been identified to target the Forkhead box O (FOXO) transcription factors and the tuberous sclerosis complex subunit 1 (TSC1) [23]. FOXO is a key substrate of AKT. AKT-mediated phosphorylation of the transcription factor FOXO can increase proliferation and survival. TSC1 and TSC2 form a complex that inhibits the activity of the small G protein Rheb. AKT-mediated phosphorylation of TSC2 relieves its inhibition of Rheb activity, leading to the activation of mTORC1 [22]. Nuclear factor kappa B (NF- $\mathrm{kB}$ ) functions as a dimeric transcription factor that regulates the expression of genes influencing a broad range of biological processes including innate and adaptive immunity, inflammation, stress responses, B-cell development, and lymphoid organogenesis [24].

Signal transducer and activator of transcription-3 (STAT-3) is a member of a family of seven proteins (STATs 1, 2, 3, 4, 5a, 5b, and 6) that relay signals from activated cytokine 
and growth factor receptors in the plasma membrane to the nucleus, where they regulate gene transcription. STAT-3 activated genes block apoptosis, favor cell proliferation and survival, promote angiogenesis and metastasis, and inhibit antitumor immune responses [25]. Among these seven STAT proteins, STAT-3 plays a critical role in angiogenesis [26,27].

Many clinical trials have demonstrated that GC patients can benefit from angiogenesis inhibitors [28-30]. Ramucirumab is a monoclonal antibody that selectively binds to VEGFR-2, blocking the downstream effects of the VEGF pathway in angiogenesis. The survival benefits in the REGARD [31] and RAINBOW [32] studies led to the approval of ramucirumab for the treatment of advanced GC (hazard ratio (HR) for overall survival (OS): 0.776, 95\% confidence interval (CI): 0.603-0.998, $p=0.047$; HR for OS: 0.807, 95\% CI: $0.678-0.962, p<0.0001$, respectively; and HR for progression-free survival (PFS): $0.483,95 \%$ CI: $0.376-0.620, p<0.0001$, HR for PFS: $0.635,95 \%$ CI: $0.536-0.752, p<0.0001$, respectively). Recently, there has been increasing interest in the development of new anti-angiogenic options for GC. Apatinib, a tyrosine kinase inhibitor (TKI) targeting VEGFR-2, was tested in a phase III placebo-controlled trial in Chinese patients with advanced pretreated GC. Rivoceranib (apatinib) treatment significantly improved PFS and OS with compared to placebo, but with a poor clinical impact on survival outcomes (median PFS: 2.6 for apatinib vs. 1.8 months for placebo, $p<0.001$; median OS: 6.5 for apatinib vs. 4.7 months for placebo, $p<0.0149$ ) [33]. In the randomized phase III placebo-controlled ANGEL trial, including both Eastern and Western patients, rivoceranib treatment significantly improved median OS from fourth line treatment (6.43 for apatinib vs. 4.73 months for plaebo, $p=0.0195$ ), while median PFS was improved from third line treatment (2.83 for apatinib vs. 1.77 months for placebo, $p<0.0001$ ) [34]. Among ongoing and recruiting studies, a phase II trial is evaluating the combination of apatinib and the programmed death-1 (PD-1) inhibitor sintilimab in unresectable GC with oligometastases as conversion therapy (NCT04267549). In another trial, apatinib is being combined with docetaxel and S-1 as first line treatment for advanced GC (NCT03154983). Moreover, the TKI regorafenib is being tested as maintenance treatment after first-line treatment for metastatic GC and absence of progression (NCT03627728). Lastly, a phase I/II trial is testing ramucirumab together with the poly ADP-ribose polymerase (PARP) inhibitor olaparib in advanced and unresectable GC (NCT03008278), while a phase II study is comparing ramucirumab plus 5-fluorouracil and irinotecan (FOLFIRI) to ramucirumab plus standard paclitaxel in second-line treatment (NCT03081143).

Although angiogenesis inhibitors can improve OS and PFS and achieve a better response rate in advanced GC, the clinical effect is quite different in individuals due to tumor heterogeneity. Therefore, it is essential to develop biomarkers that allow for identifying the subgroup of GC patients who would benefit from this type of therapy. These biomarkers could be used to predict efficacy and choose the most suitable patients to reduce unnecessary toxicity while maximizing clinical benefit [35].

\subsection{MicroRNAs and Cancer}

MicroRNAs (miRNAs) are a class of evolutionally conserved single-stranded noncoding RNAs of 19-22 nucleotides in length [36]. MiRNAs play an important role (via post-transcriptional regulation) in essentially all biologic processes such as cell proliferation, differentiation, apoptosis, survival, invasion, and migration [37]. MiRNAs form the RNA-inducing silencing complex (RISC)-miRNA functional unit, which regulates the expression of nearly 30\% of known human genes [38] (Figure 1). 


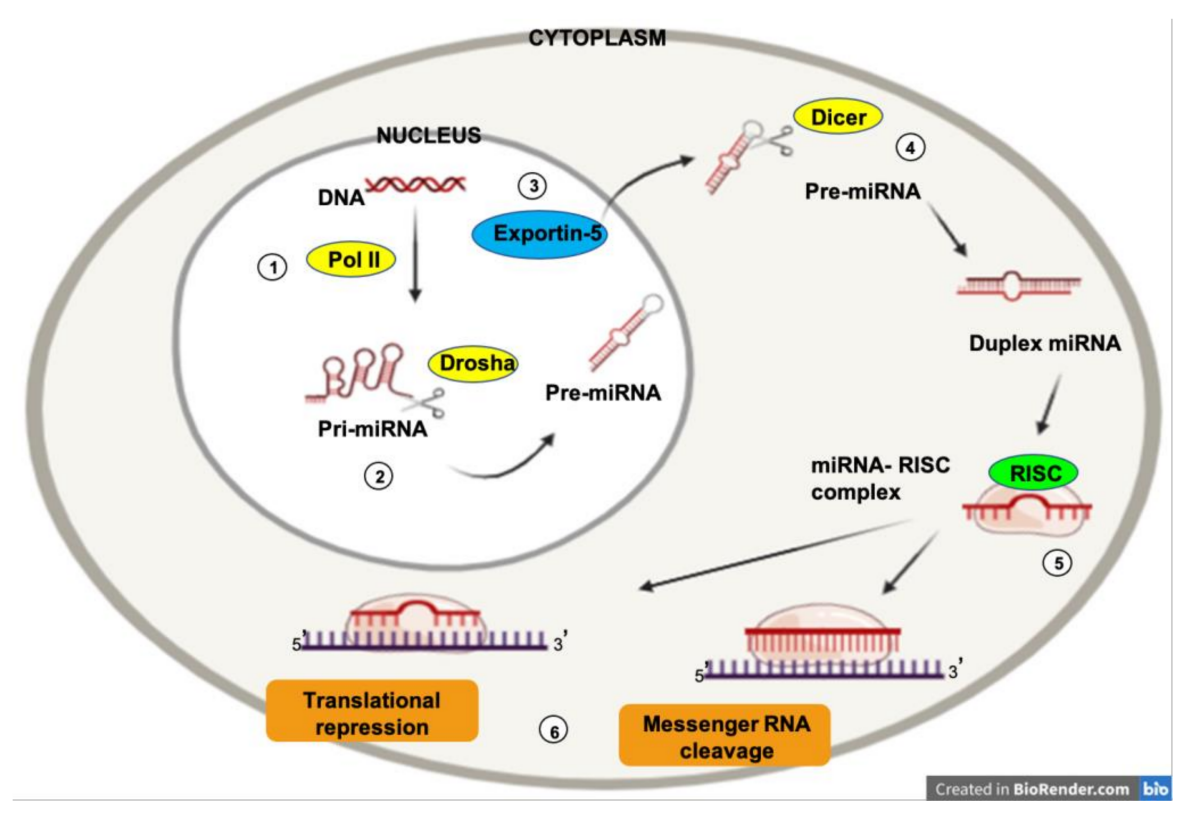

Figure 1. The expression of micro RNAs (miRNAs) is a complex biological process. RNA polymerase II is responsible for the transcription of a precursor RNA, several thousand nucleotides long and with a loop (hairpin) shape, known as "primary miRNA" (pri-miRNA) (1). The nuclear endonuclease Drosha processes the pri-miRNAs by cleaving the distal portion and making shorter chains (70-100 nucleotides) (2). This yields the pre-miRNA, which is transported into the cytoplasm via the nuclear receptor exportin-5 (3). Once in the cytoplasm, the Dicer enzyme processes the pre-miRNA to obtain a short (19-25 nucleotides) double chain RNA sequence (4). Subsequently, one of the two chains is rapidly degraded, while the remainder represents the mature miRNA. Once processed, mature miRNAs can interact with Ago2, an enzyme of the Argonaute family of endonucleases, to form so-called RNA-induced silencing complexes (RISCs) (5). This allows the interaction between the mature miRNA and the target mRNA (6). The miRNA can then perform its function (degradation or translational repression).

Nowadays, several detection methods are available for miRNAs. Among conventional techniques, Northern blotting analysis consists of the separation of RNA from the sample through denaturing gel electrophoresis with subsequent hybridization using a nucleic acid probe complementary to the target RNA. Differently, in situ hybridization uses labeled complementary nucleic acid probes to detect RNA in tissue sections or fixed cells. Similarly, microarrays rely on hybridization between target molecules and complementary probes. Reverse transcription (RT) quantitative polymerase chain reaction (qPCR) consists of two different steps: firstly, complementary DNA (cDNA) is synthetized using RT, secondly the product is amplified and detected using either intercalating dye or TaqMan probes [39]. The most innovative techniques include next-generation sequencing (NGS) methods and digital-droplet PCR (ddPCR). NGS is characterized by high data throughput. NGS uses cDNA from RNA reverse transcription. DNA is amplified many times in parallel and then sequenced multiple times simultaneously [40]. The ddPCR system has shown superior precision and sensitivity with respect to $\mathrm{qPCR}$, being able to detect very low concentrations of target nucleic acids [41]. This technique is based on the partitioning of the nucleic acid sample into thousands of oil dispersed nanodroplets containing nucleic acid. Later, PCR amplification is carried out within each droplet [42]. Three basic mechanisms of miRNA-mediated gene regulation are known: translation repression, direct mRNA degradation, and miRNA-mediated mRNA decay [43]. Many studies have demonstrated that mutations in miRNA-encoding genes or the deregulated expression of miRNAs are integral to many human diseases, including cancer development and metastasis [44]. Thus, they can act as oncogenes or tumor suppressors depending on the function of their target 
genes. As a consequence, microRNAs have shown great promise for use in anti-metastatic cancer therapy.

\subsection{MicroRNAs and Angiogenesis}

Several miRNAs have been shown to be involved in neoplastic angiogenesis. In particular, VEGF expression in different types of cancer has been recognized to be regulated by different miRNAs, such as miR-20 [45], miR-29b [46], miR-93 [47], miR-126 [48], miR190 [49], miR-195 [50], miR-200 [51], miR-203 [52], miR-497 [53], miR-503 [54], and miR638 [55]. Some of these, such as miR-29, inhibit angiogenesis by downregulating VEGF when it is overexpressed. Others, such as miRNA-195, promote angiogenesis and metastasis via VEGF and pro-metastatic factors. Apart from directly targeting VEGF, a handful of miRNAs regulate VEGF-dependent tumor angiogenesis by targeting VEGF inducers, such as the HIF-1 pathway (miR-22 [56], miR-107 [57], miR-519c [58], miR-145 [59]). However, a direct connection between the role of miRNAs in angiogenesis and cancer metastasis remains to be established.

In this review, we will summarize the current evidence, provide new insights and discuss the main challenges around angiogenesis-related miRNAs in GC. Furthermore, our study will analyze the diagnostic and prognostic role of angiogenesis-related miRNAs as novel biomarkers of GC, and potential novel GC treatments based on miRNAs that have resulted from better molecular knowledge.

\section{Materials and Methods}

We performed a comprehensive literature review of the PubMed, Scopus, and Google Scholar databases regarding angiogenesis-related miRNAs in GC, using the terms "MiRNA" AND "angiogenesis" AND ("gastric cancer" OR "gastric carcinoma" or "gastric adenocarcinoma"). The search was limited to articles published in English. We considered all the original studies regarding angiogenesis-related miRNAs in GC. A total of 75 publications were identified, from which we selected a final pool of 28 articles based on their relevance in this context.

\section{Results}

Our search identified 28 studies focused on miRNAs targeting angiogenesis in GC. The details of the selected studies are reported in Table 1. We decided to order and divide the selected miRNAs according to their referral pathway. Therefore, we identified five groups: (1) miRNAs related to the VEGF pathway, (2) miRNAs involved in the HIF pathway, (3) miRNAs related to HGF/c-MET signaling, (4) miRNAs involved in the PI3K pathway, and (5) miRNAs related to STAT-3 signaling (Table 1 and Figure 2 ). We will briefly describe the importance in the angiogenesis process of these five pathways, and we will detail, for each of them, the significant studies about angiogenesis-related miRNAs that we have found through our literature search. Some of the analyzed studies focused on different miRNAs, so we have reported the same work in the different paragraphs where indicated. 


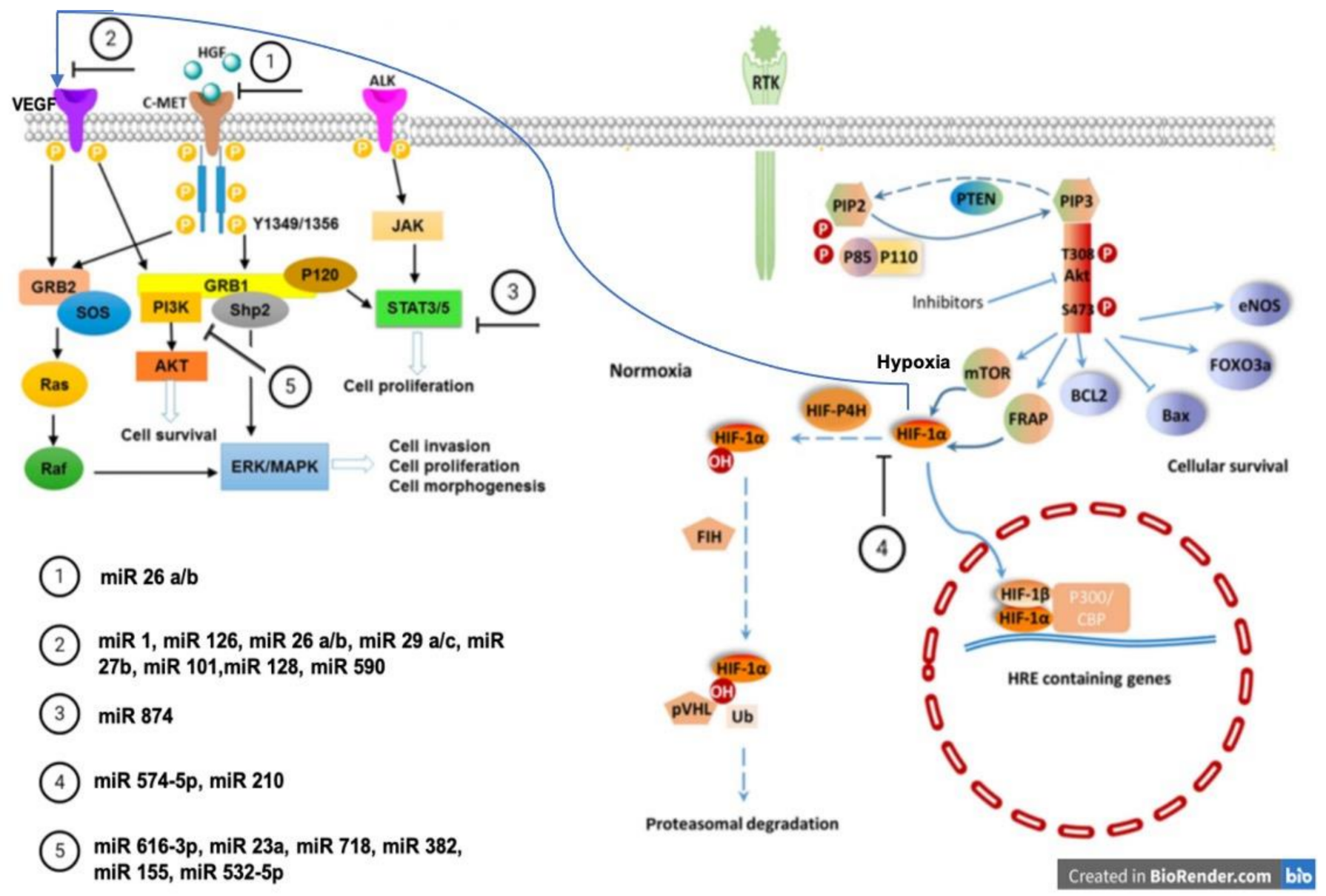

Figure 2. Major groups of micro RNAs (miRNAs) and their related pathways by which they act on endothelial cells. In normoxia, HIF- $1 \alpha$ is hydroxylated and ubiquinated. In hypoxia, hypoxia inducible factor- $1 \alpha(\mathrm{HIF}-1 \alpha)$ promotes angiogenesis by enhancing the expression of vascular endothelial growth factor-A (VEGF-A). MiRNAs act on the VEGF pathway and hepatocyte growth factor (HGF) / tyrosine-protein kinase MET (c-MET), phosphoinositide 3-kinase (PI3K), signal transducer and activation of transcription-3 (STAT-3) and HIF signaling.

\subsection{MicroRNAs Involved in the VEGF Pathway}

In this context, we have identified eight relevant published papers about miRNAs targeting VEGF signaling.

$\mathrm{Wu}$ et al. aimed to determine the potential relevance of miR-616-3p, located on the chromosome region 12q13.3, in GC tumorigenesis. In this study, miR-616-3p was demonstrated to facilitate tumor angiogenesis by elevating the expression level of VEGFA/VEGFR2 in GC [60]. A second study suggested that the downregulation of another miRNA, miR-1, could favor angiogenesis in GC. In this analysis, miR-1 was underexpressed in primary GC tissues when compared with adjacent normal mucosa and several GC cell lines. The restoration of miR-1 significantly inhibited endothelial cell tube formation by decreasing the expression of VEGF-A and endothelin 1 (EDN1), the main angiogenic factors contributing to the development and maintenance of blood vessels [23]. Additionally, the overexpression of miR-126 led to direct inhibition of VEGF-A expression, reduction of cell proliferation, and inhibition of the angiogenic process, thereby inhibiting tumor growth both in vitro and in vivo in GC [61-63]. In another work, Zhang et al. reported that the downregulation of miR-29a/c increases VEGF expression and release in GC cells, with subsequent growth promotion of endothelial cells. MiR-29a/c significantly suppressed VEGF expression in GC cells, inhibiting cell growth and metastasis. By using a tumor mouse model, it was shown that secreted microvessels (MV) overexpressing miR-29a/c significantly reduced the growth of vasculature and tumors in vivo [64]. 
In addition, VEGF-C was found to be a direct target gene of three other miRNAs, miR-27b, miR-101, and miR-128 [65]. The expression levels of these miRNAs were inversely correlated with higher MV density. Thus, the overexpression of miR-27b, miR-101, or miR-128 was demonstrated to suppress migration, proliferation, and tube formation in human umbilical vascular endothelial cells (HUVECs) by repressing VEGF-C secretion in GC cells. MiR-27b, miR-101 and miR-128 inhibit angiogenesis by downregulating VEGF$\mathrm{C}$ expression in GC [65]. Mei et al. reported that miR-590 can simultaneously regulate VEGFR1/2 in GC. In this study, miR-590 has also been shown to contribute to the regulation of the expression of neuropilin 1 (NRP1) in GC. NRP1 is a transmembrane protein that can bind the VEGF 165 isoform and enhance cell migration via VEGFR2, also inducing vascular permeability and arteriogenesis. The authors reported that miR-590 was downregulated in GC tissues and cell lines, and this was related to the dysregulation of the transcription factor SNAIL. SNAIL inhibited the expression of miR-590, thereby upregulating the expression levels of NRP1 and VEGFR1/2; this led to the promotion of the epithelial-mesenchymal transition (EMT) process in GC and the upregulation of SNAIL. In addition, the overexpression of miR-590 inhibited the migration, invasion, proliferation, and digital microvascular (D-MVA) levels of gastric cancer cells in vivo and in vitro by targeting VEGFR1/2 and NRP1 [66].

\subsection{MicroRNAs Involved in the HIF Pathway}

In our search, we identified two studies reporting data about the aberrant expression in GC of HIF-related miRNAs. The first study by Zhang et al. demonstrated how under hypoxic conditions (GC cells cultured under $2 \% \mathrm{O}_{2}$ or in medium containing $\mathrm{CoCl}_{2}$ ), $\mathrm{HIF}-1$ elevation leads to an increase in the miR-574-5p expression level in GC cells. The authors suggested that the molecular mechanism involves miR-574-5p activating 44/42 kilodaltons $(\mathrm{kDa})$ mitogen-activated protein kinases (MAPKs) by suppressing the expression of its target gene, PTPN3 (a protein tyrosine phosphorylase), thereby promoting angiogenesis by enhancing the expression of VEGF-A [67]. Furthermore, the authors confirmed the role of miR-574-5p in mice tumor xenografts. In this model, the inhibition of miR-574-5p reduced the expression of CD31, a well-known endothelial cell marker [67].

In the second study, Seo et al. reported that another miRNA, miR-210, was found to be progressively upregulated in response to HIFs in hypoxic conditions in GC. In this work, miR-210 was identified as a hypoxia-induced miRNA that plays key roles in biological processes such as cell cycle progression, metabolism, apoptosis, angiogenesis, and metastasis [68].

\subsection{MicroRNAs Involved in HGF/c-MET Signaling}

In this context, we identified one study, carried out by $\mathrm{Si}$ et al., in which this signaling pathway has been demonstrated to be involved in GC angiogenesis by miRNA deregulation. In this study, the authors focused on miR-26a/b, which can potentially target HGF in GC. As a result, HGF was upregulated in GC in vivo and in vitro, while miR-26a/b was significantly downregulated. The authors found that the expression of VEGF was induced by HGF, and HGF was upregulated as a result of the downregulation of miR-26a/b. Thus, $\mathrm{miR}-26 \mathrm{a} / \mathrm{b}$ appears to promote angiogenesis in GC [69].

\subsection{MicroRNAs Involved in the PI3K Pathway}

In our literature search, we identified 11 relevant studies about miRNAs pertaining to this signaling pathway: four studies describe miRNAs that target PTEN; in three studies, the target was FOXO; three studies reported miRNAs targeting mTOR; and in one study, the target was NF- $\mathrm{kB}$.

\subsubsection{MicroRNAs Targeting PTEN}

In one study, miR-23a was augmented in HGC-27-derived exosomes, and facilitated angiogenesis by targeting PTEN, as verified by the elevated expression level of VEGF and 
the reduced expression level of the matricellular protein thrombospondin-1 (TSP-1) [23]. The same study demonstrated that the upregulation of another miRNA, miR-616-3p, in GC tissues resulted in the downregulation of PTEN and PI3K/AKT/mTOR pathway activation through PTEN, which then contributed to EMT and angiogenesis [23]. A second study confirmed the relevance of miR-23a, and a third study confirmed the relevance of miR-616-3p in GC $[60,70]$. In the study by Du et al., miR-23a was highly expressed in GC tissues, cells, and GC cell-derived exosomes. This miRNA was demonstrated to promote angiogenesis via the repression of PTEN in a co-culture system [70]. The role of miR-616-3p as a promoter of angiogenesis via the PTEN/AKT/mTOR pathway in GC has also been confirmed in the study by Wu et al. [60]. Two other miRNAs, miR-718 and miR-382, have been suggested to target PTEN, thus inhibiting the angiogenesis and progression of GC [71]. In this study by Liu et al., the low expression of PTEN and increased expression of miR-718 were demonstrated to be independent unfavorable prognostic factors for GC [71].

\subsubsection{MicroRNAs Targeting FOXO}

Two studies reported that miR-155 alone and in GC-derived exosomes could promote angiogenesis in in vitro models of GC by inhibiting FOXO3a expression. MiR-155 also seemed to have the same role in vivo, where it was shown to facilitate angiogenesis in GC $[72,73]$. Similarly, miR-135b was found to suppress the expression of the FOXO1 protein and enhanced the growth of blood vessels in GC [74].

\subsubsection{MicroRNAs Targeting mTOR}

The overexpression of miR-18a was shown to inactivate the mTOR pathway and downregulate HIF1 $\alpha$ and VEGF expression in a GC cell line named SGC-7901. Furthermore, miR-18a was identified as the cause of the substantial reduction in the number of microvessels in an SGC-7901 xenograft model of GC [63].

Emerging data showed that the circulating miR-17-92 expression level was significantly different between GC individuals and healthy controls, implying that miR-17-92 may be a potential biomarker for GC. In this study, miR-17-92 levels were associated with the progression of advanced GC and the effectiveness of capecitabine and oxaliplatin (CAPOX) chemotherapy [75]. Another work reported that the exogenous expression of miR-101-2, miR-125b-2, and miR-451a decreased the expression of their putative targets mTOR, PIK3CB and TSC1, respectively [76].

\subsubsection{MicroRNAs Targeting NF- $\mathrm{kB}$}

Finally, a study by Zhang et al. demonstrated that miR-532-5p attenuated NF- $\mathrm{kB}$ signaling by directly inhibiting NCF2 expression, while miR-532-5p silencing in GC enhanced NF- $\mathrm{kB}$ activity. MiR-532-5p overexpression inhibited GC metastasis and angiogenesis in vitro and in vivo, whereas miR-532-5p silencing had the opposite effect. Furthermore, it was demonstrated that miR-532-5p downregulation was caused by the aberrantly high expression of a long non-coding RNA (lncRNA), LINC01410, in GC [77]. Mechanistically, the overexpression of LINC01410 promoted GC angiogenesis and metastasis by binding to and suppressing miR-532-5p, which resulted in the upregulation of NCF2 and sustained NF- $\mathrm{kB}$ pathway activation. Interestingly, NCF2 could, in turn, increase the promoter activity and expression of LINC01410 via NF- $\mathrm{kB}$, thus forming a positive feedback loop driving the malignant behavior of GC [77].

\subsection{MicroRNAs Involved in STAT-3 Signaling}

In our literature search, we identified a study analyzing the effect of miR-874 on the VEGF-A gene in GC. This study demonstrated that the overexpression of this miRNA determined the inhibition of STAT-3 gene expression, leading to the inhibition of VEGF-A expression and, in turn, to a reduction in tumor growth and angiogenesis in vitro and in vivo [78]. These results suggested that miR-874 overexpression may inhibit the VEGF-A 
pathway, angiogenesis, and tumor growth by acting on the Janus kinase/signal transducers and activators of transcription (JAK/STAT) pathway in GC [62].

Table 1. MiRNA classification based on referral pathways.

\begin{tabular}{|c|c|c|c|}
\hline miRNA & Target Genes & Classification & Reference \\
\hline miR-1 & $\begin{array}{l}\text { VEGF-A } \\
\text { EDN1 } \\
\text { MET }\end{array}$ & VEGF pathway & Azarbarzin et al., 2020 [23] \\
\hline $\mathrm{miR}-29 \mathrm{a} / \mathrm{c}$ & VEGF & VEGF pathway & Zhang et al., 2016 [64] \\
\hline $\begin{array}{l}\operatorname{miR}-27 b \\
\operatorname{miR}-101 \\
\operatorname{miR}-128\end{array}$ & VEGF-C & VEGF pathway & Liu et al., 2015 [65] \\
\hline miR-126 & VEGF-A & VEGF pathway & $\begin{array}{l}\text { Cuzziol et al., } 2020 \text { [62] } \\
\text { Yang et al., } 2015 \text { [63] }\end{array}$ \\
\hline miR-590 & $\begin{array}{c}\text { VEGFR1/2 } \\
\text { NRP1 }\end{array}$ & VEGF pathway & Mei et al., 2020 [66] \\
\hline $\operatorname{miR}-210$ & HIF & HIF pathway & Seo et al., 2019 [68] \\
\hline $\operatorname{miR}-574-5 p$ & PTPN3 & HIF pathway & $\begin{array}{c}\text { Azarbarzin et al., } 2020 \text { [23] } \\
\text { Zhang et al., } 2020 \text { [67] }\end{array}$ \\
\hline miR-616-3p & PTEN & $\begin{array}{l}\text { PI3K pathway } \\
\text { VEGF pathway }\end{array}$ & Wu et al., 2018 [60] \\
\hline $\operatorname{miR}-26 a / b$ & HGF & $\begin{array}{l}\text { HGF/c-MET } \\
\text { signaling }\end{array}$ & Si et al., 2017 [69] \\
\hline miR-18a & mTOR & PI3K pathway & Yang et al., 2015 [63] \\
\hline miR-23a & PTEN & PI3K pathway & $\begin{array}{c}\text { Azarbarzin et al., } 2020 \text { [23] } \\
\text { Du et al., } 2020 \text { [70] }\end{array}$ \\
\hline $\begin{array}{l}\operatorname{miR}-101-2 \\
\operatorname{miR}-125 b-2 \\
\text { miR-451a }\end{array}$ & mTOR/PIK3CB/TSC1 & $\begin{array}{l}\text { PI3K pathway } \\
\text { PI3K pathway } \\
\text { PI3K pathway }\end{array}$ & Riquelme et al., 2016 [76] \\
\hline $\operatorname{miR}-135 b$ & FOXO1 & PI3K pathway & Bai et al., 2019 [74] \\
\hline miR-382 & PTEN & PI3K pathway & $\begin{array}{l}\text { Du et al., } 2020[70] \\
\text { Seo et al., } 2019 \text { [68] }\end{array}$ \\
\hline miR-532-5p & NCF2 & PI3K pathway & Zhang et al., 2018 [75] \\
\hline $\operatorname{miR}-718$ & PTEN & PI3K pathway & Du et al., 2020 [70] \\
\hline miR-155 & $\begin{array}{l}\text { c-MYB/VEGF } \\
\text { FOXO3a }\end{array}$ & $\begin{array}{l}\text { Other-c-MYB } \\
\text { PI3K pathway }\end{array}$ & $\begin{array}{c}\text { Azarbarzin et al., } 2020 \text { [23] } \\
\text { Deng et al., } 2020 \text { [72] } \\
\text { Zhou et al., } 2019 \text { [73] }\end{array}$ \\
\hline $\operatorname{miR}-874$ & STAT-3/VEGF-A & STAT-3 signaling & $\begin{array}{l}\text { Cuzziol et al., } 2020 \text { [62] } \\
\text { Zhang et al., } 2015 \text { [78] }\end{array}$ \\
\hline
\end{tabular}

\section{Discussion}

The search for prognostic and predictive biomarkers has been a major objective, together with the development of new treatment options, in oncology in the last few decades. Much investigation has been carried out in order to identify predictive biomarkers of a response to targeted agents and mechanisms of resistance to the same drugs in advanced GC. In this context, several potentially useful biomarkers have been extensively investigated to determine their role in selecting the best candidates for anti-angiogenic therapies in GC. High tissue expression of VEGF-A and -C was found to be correlated with poor prognosis and a higher risk of relapse in patients with resected GC [79-81]. The promotion of angiogenesis is typical of chromosome unstable tumors, accounting for the majority ( $50 \%$ ) of GC. These tumors typically harbor the overexpression of the gene 
encoding VEGF-A [82]. On the other hand, although ramucirumab acts by blocking the downstream effects of the VEGF pathway, VEGF subtype expression has never been shown to be a predictor of response to anti-angiogenic treatment in GC. Relevant examples of the highly unsatisfactory results obtained are represented by the biomarker analysis of two placebo-controlled, phase III randomized clinical trials, REGARD and RAINBOW. An exploratory biomarker analysis in the REGARD trial tested VEGFR expression with immunohistochemistry (IHC), while serum samples were assayed for VEGF-C and -D and sVEGFR-1 and -3 . The results were not able to identify a strong potentially predictive biomarker of ramucirumab efficacy [83]. Similarly, the biomarker analysis in the RAINBOW study was unsuccessful in identifying circulating predictive factors in plasma samples of GC patients [84]. Ramucirumab is frequently used in combination with paclitaxel because the combination of both drugs has a synergistic inhibitory effect on cell growth [85]. Ramucirumab acts by enhancing the growth inhibition of paclitaxel and the inhibitory effects of chemotherapy on cell migration and actin polymerization. Moreover, the two agents modulate the cell expression of VEGF-A and VEGFR-2 and the signaling of MAPK and the $\mathrm{PI} 3 \mathrm{~K} / \mathrm{AKT} / \mathrm{mTOR}$ pathways [85].

Therefore, there is an urgent need to identify innovative biomarkers that are useful to select patients for anti-angiogenic treatment. MiRNAs harbor promising value as predictive and prognostic biomarkers in different types of tumors, including GC [86-88]. Indeed, miRNAs are involved in cell cycle regulation and in key processes of tumorigenesis in GC $[89,90]$.

Focusing on angiogenesis, many miRNAs act by interfering with angiogenetic pathways (such as VEGF, HIF, HGF/c-MET, and others) and may play both a prognostic and a predictive role in this setting. Within the VEGF pathway, miR-616-3p was reported to be upregulated in hepatocellular carcinoma and in prostate, lung, and breast cancer [91]. In our analysis, interesting data emerged about this miRNA in GC [60]. Another miRNA involved in the same pathway, miR-126 [92,93], was recognized as a promising therapeutic target in several types of tumors, including GC [94]. MiR-126 is an endothelial-specific miRNA essential for governing vascular integrity and angiogenesis. Previous studies demonstrated that reduced expression of this miRNA may be associated with progression and poor outcomes in lung cancer [95]. Notably, the predictive value of this miRNA has been shown in a study including 68 colorectal cancer patients treated with the antiangiogenic drug bevacizumab [96]. The authors demonstrated a separation of responders and non-responders in the PFS analysis, with better outcomes for patients with decreased miR-126 levels, (HR: 0.60, $p=0.07$ ). Many works reported in our paper suggested a similar potential role for this miRNA [61-63]. Considering the HIF pathway, miR-210 is of particular relevance. This miRNA has been demonstrated to be differentially expressed in healthy controls and in patients affected by lung cancer [97]. Other evidence suggested a prognostic role for miR-210 in metastatic renal cell carcinoma [98], as well as in osteosarcoma [99]. Furthermore, considering the PI3K signaling pathway, we identified 11 relevant studies about miRNAs with promising value as predictive or prognostic biomarkers in GC. Of these, miR-18a was identified as a promising prognostic marker in lung and bladder cancer [100]. This miRNA has also been evaluated as a potential diagnostic marker for GC [63]. Similar results were reported for colorectal cancer [101]. Belonging to the same pathway, miR-17-92 showed a predictive role with respect to capecitabine and oxaliplatin chemotherapy in GC patients [75]. Notably, the prognostic and predictive values of this miRNA in rectal cancer patients has also been described [102]. Finally, miR-874, related to the STAT-3 pathway, has emerged as a potentially useful diagnostic biomarker for colorectal cancer (CRC) [103]. In this study, miR-874 levels were significantly downregulated in CRC patients compared to healthy controls. Similarly, miR-874 has been recognized as playing a tumor suppressor role in non-small cell lung cancer (NSCLC) both in vitro and in vivo [104]. Similar results have been achieved in pancreatic cancer [105].

Therefore, the data collected and analyzed in this review suggest that different angiogenesis-related miRNAs could potentially represent innovative diagnostic and prog- 
nostic biomarkers for advanced GC patients. Additionally, some of these miRNAs may be correlated with benefit and toxicity to anti-angiogenic agents in this group of patients, even though these data have not been validated prospectively.

\section{Conclusions}

MiRNAs are involved in the regulation of neoplastic angiogenesis, which is a crucial mechanism in GC onset and progression.

In future studies, miRNAs should be evaluated as candidate biomarkers with prognostic and predictive features, especially in the majority of GC cases that harbor a proangiogenic molecular signature. High data throughput techniques such as NGS may be used in sub-analyses of large clinical trials, both on available tissue samples and liquid biopsies. In this way, the identified miRNAs may be associated with survival outcomes and clinical response to therapies.

Author Contributions: Conceptualization, M.G. (Michele Ghidini) and A.L.S.; methodology, M.G. (Michele Ghidini); software, M.G. (Michele Ghidini) and A.L.S.; validation, M.G. (Michele Ghidini), M.G. (Martina Giuppi) and A.L.S.; formal analysis, M.G. (Martina Giuppi); investigation, A.L.S.; resources, M.G. (Michele Ghidini); data curation, M.G. (Martina Giuppi) and A.L.S.; writing-original draft preparation, M.G. (Michele Ghidini), M.G. (Martina Giuppi) and A.L.S.; writing-review and editing, J.E.; visualization, J.E.; supervision, J.E.; project administration, J.E.; funding acquisition, M.G. (Michele Ghidini) All authors have read and agreed to the published version of the manuscript.

Funding: This research received no external funding.

Institutional Review Board Statement: Not applicable.

Informed Consent Statement: Not applicable.

Data Availability Statement: Not applicable.

Conflicts of Interest: The authors declare no conflict of interest.

\section{References}

1. Hanahan, D.; Weinberg, R.A. Hallmarks of cancer: The next generation. Cell 2011, 144, 646-674. [CrossRef]

2. Lee, S.L.; Rouhi, P.; Dahl Jensen, L.; Zhang, D.; Ji, H.; Hauptmann, G.; Ingham, P.; Cao, Y. Hypoxia-induced pathological angiogenesis mediates tumor cell dissemination, invasion, and metastasis in a zebrafish tumor model. Proc. Natl. Acad. Sci. USA 2009, 106, 19485-19490. [CrossRef]

3. Wang, Z.; Dabrosin, C.; Yin, X.; Fuster, M.M.; Arreola, A.; Rathmell, W.K.; Generali, D.; Nagaraju, G.P.; El-Rayes, B.; Ribatti, D.; et al. Broad targeting of angiogenesis for cancer prevention and therapy. Semin. Cancer Biol. 2015, 35, S224-S243. [CrossRef]

4. Calabrese, C.; Poppleton, H.; Kocak, M.; Hogg, T.L.; Fuller, C.; Hamner, B.; Oh, E.Y.; Gaber, M.W.; Finklestein, D.; Allen, M.; et al. A perivascular niche for brain tumor stem cells. Cancer Cell 2007, 11, 69-82. [CrossRef]

5. Lathia, J.D.; Heddleston, J.M.; Venere, M.; Rich, J.N. Deadly teamwork: Neural cancer stem cells and the tumor microenvironment. Cell Stem Cell 2011, 8, 482-485. [CrossRef]

6. Herbert, S.P.; Stainier, D.Y. Molecular control of endothelial cell behaviour during blood vessel morphogenesis. Nat. Rev. Mol. Cell Biol. 2011, 12, 551-564. [CrossRef]

7. Hanahan, D.; Folkman, J. Patterns and emerging mechanisms of the angiogenic switch during tumorigenesis. Cell 1996, 86, 353-364. [CrossRef]

8. Baeriswyl, V.; Christofori, G. The angiogenic switch in carcinogenesis. Semin. Cancer Biol. 2009, 19, 329-337. [CrossRef] [PubMed]

9. Bergers, G.; Benjamin, L.E. Tumorigenesis and the angiogenic switch. Nat. Rev. Cancer 2003, 3, 401-410. [CrossRef] [PubMed]

10. Wang, Y.; Wang, L.; Chen, C.; Chu, X. New insights into the regulatory role of microRNA in tumor angiogenesis and clinical implications. Mol. Cancer 2018, 17, 22. [CrossRef] [PubMed]

11. Lieto, E.; Ferraraccio, F.; Orditura, M.; Castellano, P.; Mura, A.L.; Pinto, M.; Zamboli, A.; De Vita, F.; Galizia, G. Expression of vascular endothelial growth factor (VEGF) and epidermal growth factor receptor (EGFR) is an independent prognostic indicator of worse outcome in gastric cancer patients. Ann. Surg. Oncol. 2008, 15, 69-79. [CrossRef]

12. Holmes, D.I.; Zachary, I. The vascular endothelial growth factor (VEGF) family: Angiogenic factors in health and disease. Genome Biol. 2005, 6, 209. [CrossRef]

13. Forma, A.; Tyczynska, M.; Kedzierawski, P.; Gietka, K.; Sitarz, M. Gastric carcinogenesis: A comprehensive review of the angiogenic pathways. Clin. J. Gastroenterol. 2020, 1-12. [CrossRef] 
14. Peng, L.; Zhan, P.; Zhou, Y.; Fang, W.; Zhao, P.; Zheng, Y.; Xu, N. Prognostic significance of vascular endothelial growth factor immunohistochemical expression in gastric cancer: A meta-analysis. Mol. Biol. Rep. 2012, 39, 9473-9484. [CrossRef]

15. Ziello, J.E.; Jovin, I.S.; Huang, Y. Hypoxia-Inducible Factor (HIF)-1 regulatory pathway and its potential for therapeutic intervention in malignancy and ischemia. Yale J. Biol. Med. 2007, 80, 51-60. [PubMed]

16. Basilico, C.; Arnesano, A.; Galluzzo, M.; Comoglio, P.M.; Michieli, P. A high affinity hepatocyte growth factor-binding site in the immunoglobulin-like region of Met. J. Biol. Chem. 2008, 283, 21267-21277. [CrossRef] [PubMed]

17. Organ, S.L.; Tsao, M.S. An overview of the c-MET signaling pathway. Ther. Adv. Med. Oncol. 2011, 3, S7-S19. [CrossRef] [PubMed]

18. Birchmeier, C.; Birchmeier, W.; Gherardi, E.; Vande Woude, G.F. Met, metastasis, motility and more. Nat. Rev. Mol. Cell Biol. 2003, 4, 915-925. [CrossRef] [PubMed]

19. Trusolino, L.; Comoglio, P.M. Scatter-factor and semaphorin receptors: Cell signalling for invasive growth. Nat. Rev. Cancer 2002, 2, 289-300. [CrossRef] [PubMed]

20. Chalhoub, N.; Baker, S.J. PTEN and the PI3-kinase pathway in cancer. Annu. Rev. Pathol. 2009, 4, 127-150. [CrossRef] [PubMed]

21. Engelman, J.A.; Luo, J.; Cantley, L.C. The evolution of phosphatidylinositol 3-kinases as regulators of growth and metabolism. Nat. Rev. Genet. 2006, 7, 606-619. [CrossRef]

22. Sun, P.; Meng, L.H. Emerging roles of class I PI3K inhibitors in modulating tumor microenvironment and immunity. Acta Pharmacol. Sin. 2020, 41, 1395-1402. [CrossRef]

23. Azarbarzin, S.; Safaralizadeh, R.; Khojasteh, M.B.; Baghbanzadeh, A.; Baradaran, B. Current perspectives on the dysregulated microRNAs in gastric cancer. Mol. Biol. Rep. 2020, 47, 7253-7264. [CrossRef]

24. Hayden, M.S.; Ghosh, S. Shared principles in NF-kappaB signaling. Cell 2008, 132, 344-362. [CrossRef]

25. Johnston, P.A.; Grandis, J.R. STAT3 signaling: Anticancer strategies and challenges. Mol. Interv. 2011, 11, 18-26. [CrossRef]

26. Bartoli, M.; Platt, D.; Lemtalsi, T.; Gu, X.; Brooks, S.E.; Marrero, M.B.; Caldwell, R.B. VEGF differentially activates STAT3 in microvascular endothelial cells. FASEB J. 2003, 17, 1562-1564. [CrossRef]

27. Chen, Z.; Han, Z.C. STAT3: A critical transcription activator in angiogenesis. Med. Res. Rev. 2008, 28, 185-200. [CrossRef] [PubMed]

28. Ferrara, N.; Hillan, K.J.; Gerber, H.P.; Novotny, W. Discovery and development of bevacizumab, an anti-VEGF antibody for treating cancer. Nat. Rev. Drug Discov. 2004, 3, 391-400. [CrossRef] [PubMed]

29. Ferrara, N.; Kerbel, R.S. Angiogenesis as a therapeutic target. Nature 2005, 438, 967-974. [CrossRef] [PubMed]

30. Kerbel, R.S. Tumor angiogenesis. N. Engl. J. Med. 2008, 358, 2039-2049. [CrossRef] [PubMed]

31. Fuchs, C.S.; Tomasek, J.; Yong, C.J.; Dumitru, F.; Passalacqua, R.; Goswami, C.; Safran, H.; Dos Santos, L.V.; Aprile, G.; Ferry, D.R.; et al. Ramucirumab monotherapy for previously treated advanced gastric or gastro-oesophageal junction adenocarcinoma (REGARD): An international, randomised, multicentre, placebo-controlled, phase 3 trial. Lancet 2014, 383 , 31-39. [CrossRef]

32. Wilke, H.; Muro, K.; Van Cutsem, E.; Oh, S.C.; Bodoky, G.; Shimada, Y.; Hironaka, S.; Sugimoto, N.; Lipatov, O.; Kim, T.Y.; et al. Ramucirumab plus paclitaxel versus placebo plus paclitaxel in patients with previously treated advanced gastric or gastrooesophageal junction adenocarcinoma (RAINBOW): A double-blind, randomised phase 3 trial. Lancet Oncol. 2014, 15, 1224-1235. [CrossRef]

33. Li, J.; Qin, S.; Xu, J.; Xiong, J.; Wu, C.; Bai, Y.; Liu, W.; Tong, J.; Liu, Y.; Xu, R.; et al. Randomized, Double-Blind, Placebo-Controlled Phase III Trial of Apatinib in Patients With Chemotherapy-Refractory Advanced or Metastatic Adenocarcinoma of the Stomach or Gastroesophageal Junction. J. Clin. Oncol. 2016, 34, 1448-1454. [CrossRef] [PubMed]

34. Kang, Y.; Kang, W.K.; Di Bartolomeo, M.; Chau, H.H.; Yoon, S.; Cascinu, S.; Ryu, M.; Kim, J.C.; Lee, K.; Oh, S.C.; et al. Randomized phase III ANGEL study of rivoceranib (apatinib) + best supportive care (BSC) vs placebo + BSC in patients with advanced/metastatic gastric cancer who failed $\geq 2$ prior chemotherapy regimens. Ann. Oncol. 2019, 30 (Suppl. 5), v851-v934. [CrossRef]

35. Yu, J.; Zhang, Y.; Leung, L.H.; Liu, L.; Yang, F.; Yao, X. Efficacy and safety of angiogenesis inhibitors in advanced gastric cancer: A systematic review and meta-analysis. J. Hematol. Oncol. 2016, 9, 111. [CrossRef] [PubMed]

36. Bartel, D.P. MicroRNAs: Genomics, biogenesis, mechanism, and function. Cell 2004, 116, 281-297. [CrossRef]

37. Winter, J.; Diederichs, S. MicroRNA biogenesis and cancer. Methods Mol. Biol. 2011, 676, 3-22. [CrossRef]

38. Kim, A.H.; Reimers, M.; Maher, B.; Williamson, V.; McMichael, O.; McClay, J.L.; van den Oord, E.J.; Riley, B.P.; Kendler, K.S.; Vladimirov, V.I. MicroRNA expression profiling in the prefrontal cortex of individuals affected with schizophrenia and bipolar disorders. Schizophr. Res. 2010, 124, 183-191. [CrossRef]

39. Dave, V.P.; Ngo, T.A.; Pernestig, A.K.; Tilevik, D.; Kant, K.; Nguyen, T.; Wolff, A.; Bang, D.D. MicroRNA amplification and detection technologies: Opportunities and challenges for point of care diagnostics. Lab. Investig. 2019, 99, 452-469. [CrossRef]

40. Robin, J.D.; Ludlow, A.T.; LaRanger, R.; Wright, W.E.; Shay, J.W. Comparison of DNA Quantification Methods for Next Generation Sequencing. Sci. Rep. 2016, 6, 24067. [CrossRef]

41. Zhao, G.; Jiang, T.; Liu, Y.; Huai, G.; Lan, C.; Li, G.; Jia, G.; Wang, K.; Yang, M. Droplet digital PCR-based circulating microRNA detection serve as a promising diagnostic method for gastric cancer. BMC Cancer 2018, 18, 676. [CrossRef] [PubMed]

42. Miotto, E.; Saccenti, E.; Lupini, L.; Callegari, E.; Negrini, M.; Ferracin, M. Quantification of circulating miRNAs by droplet digital PCR: Comparison of EvaGreen- and TaqMan-based chemistries. Cancer Epidemiol. Biomark. Prev. 2014, 23, 2638-2642. [CrossRef] [PubMed] 
43. Guo, H.; Ingolia, N.T.; Weissman, J.S.; Bartel, D.P. Mammalian microRNAs predominantly act to decrease target mRNA levels. Nature 2010, 466, 835-840. [CrossRef]

44. Lages, E.; Ipas, H.; Guttin, A.; Nesr, H.; Berger, F.; Issartel, J.P. MicroRNAs: Molecular features and role in cancer. Front. Biosci. 2012, 17, 2508-2540. [CrossRef]

45. Lei, Z.; Li, B.; Yang, Z.; Fang, H.; Zhang, G.M.; Feng, Z.H.; Huang, B. Regulation of HIF-1alpha and VEGF by miR-20b tunes tumor cells to adapt to the alteration of oxygen concentration. PLoS ONE 2009, 4, e7629. [CrossRef] [PubMed]

46. Chou, J.; Lin, J.H.; Brenot, A.; Kim, J.W.; Provot, S.; Werb, Z. GATA3 suppresses metastasis and modulates the tumour microenvironment by regulating microRNA-29b expression. Nat. Cell Biol. 2013, 15, 201-213. [CrossRef] [PubMed]

47. Long, J.; Wang, Y.; Wang, W.; Chang, B.H.; Danesh, F.R. Identification of microRNA-93 as a novel regulator of vascular endothelial growth factor in hyperglycemic conditions. J. Biol. Chem. 2010, 285, 23457-23465. [CrossRef]

48. Liu, B.; Peng, X.C.; Zheng, X.L.; Wang, J.; Qin, Y.W. MiR-126 restoration down-regulate VEGF and inhibit the growth of lung cancer cell lines in vitro and in vivo. Lung Cancer 2009, 66, 169-175. [CrossRef]

49. Hao, Y.; Yang, J.; Yin, S.; Zhang, H.; Fan, Y.; Sun, C.; Gu, J.; Xi, J.J. The synergistic regulation of VEGF-mediated angiogenesis through miR-190 and target genes. RNA 2014, 20, 1328-1336. [CrossRef]

50. Wang, R.; Zhao, N.; Li, S.; Fang, J.H.; Chen, M.X.; Yang, J.; Jia, W.H.; Yuan, Y.; Zhuang, S.M. MicroRNA-195 suppresses angiogenesis and metastasis of hepatocellular carcinoma by inhibiting the expression of VEGF, VAV2, and CDC42. Hepatology 2013, 58, 642-653. [CrossRef]

51. Zhang, H.F.; Xu, L.Y.; Li, E.M. A family of pleiotropically acting microRNAs in cancer progression, miR-200: Potential cancer therapeutic targets. Curr. Pharm. Des. 2014, 20, 1896-1903. [CrossRef]

52. Zhu, X.; Er, K.; Mao, C.; Yan, Q.; Xu, H.; Zhang, Y.; Zhu, J.; Cui, F.; Zhao, W.; Shi, H. miR-203 suppresses tumor growth and angiogenesis by targeting VEGFA in cervical cancer. Cell Physiol. Biochem. 2013, 32, 64-73. [CrossRef]

53. Yan, J.J.; Zhang, Y.N.; Liao, J.Z.; Ke, K.P.; Chang, Y.; Li, P.Y.; Wang, M.; Lin, J.S.; He, X.X. MiR-497 suppresses angiogenesis and metastasis of hepatocellular carcinoma by inhibiting VEGFA and AEG-1. Oncotarget 2015, 6, 29527-29542. [CrossRef]

54. Zhou, B.; Ma, R.; Si, W.; Li, S.; Xu, Y.; Tu, X.; Wang, Q. MicroRNA-503 targets FGF2 and VEGFA and inhibits tumor angiogenesis and growth. Cancer Lett. 2013, 333, 159-169. [CrossRef]

55. Cheng, J.; Chen, Y.; Zhao, P.; Liu, X.; Dong, J.; Li, J.; Huang, C.; Wu, R.; Lv, Y. Downregulation of miRNA-638 promotes angiogenesis and growth of hepatocellular carcinoma by targeting VEGF. Oncotarget 2016, 7, 30702-30711. [CrossRef]

56. Yamakuchi, M.; Yagi, S.; Ito, T.; Lowenstein, C.J. MicroRNA-22 regulates hypoxia signaling in colon cancer cells. PLoS ONE 2011, 6, e20291. [CrossRef]

57. Yamakuchi, M.; Lotterman, C.D.; Bao, C.; Hruban, R.H.; Karim, B.; Mendell, J.T.; Huso, D.; Lowenstein, C.J. P53-induced microRNA-107 inhibits HIF-1 and tumor angiogenesis. Proc. Natl. Acad. Sci. USA 2010, 107, 6334-6339. [CrossRef]

58. Cha, S.T.; Chen, P.S.; Johansson, G.; Chu, C.Y.; Wang, M.Y.; Jeng, Y.M.; Yu, S.L.; Chen, J.S.; Chang, K.J.; Jee, S.H.; et al. MicroRNA519c suppresses hypoxia-inducible factor-1alpha expression and tumor angiogenesis. Cancer Res. 2010, 70, 2675-2685. [CrossRef] [PubMed]

59. Zhang, H.; Pu, J.; Qi, T.; Qi, M.; Yang, C.; Li, S.; Huang, K.; Zheng, L.; Tong, Q. MicroRNA-145 inhibits the growth, invasion, metastasis and angiogenesis of neuroblastoma cells through targeting hypoxia-inducible factor 2 alpha. Oncogene 2014, 33, 387-397. [CrossRef] [PubMed]

60. Wu, Z.H.; Lin, C.; Liu, C.C.; Jiang, W.W.; Huang, M.Z.; Liu, X.; Guo, W.J. MiR-616-3p promotes angiogenesis and EMT in gastric cancer via the PTEN/AKT/mTOR pathway. Biochem. Biophys. Res. Commun. 2018, 501, 1068-1073. [CrossRef]

61. Chen, H.; Li, L.; Wang, S.; Lei, Y.; Ge, Q.; Lv, N.; Zhou, X.; Chen, C. Reduced miR-126 expression facilitates angiogenesis of gastric cancer through its regulation on VEGF-A. Oncotarget 2014, 5, 11873-11885. [CrossRef]

62. Cuzziol, C.I.; Castanhole-Nunes, M.M.U.; Pavarino, E.C.; Goloni-Bertollo, E.M. MicroRNAs as regulators of VEGFA and NFE2L2 in cancer. Gene 2020, 759, 144994. [CrossRef] [PubMed]

63. Yang, Q.; Zhang, R.W.; Sui, P.C.; He, H.T.; Ding, L. Dysregulation of non-coding RNAs in gastric cancer. World J. Gastroenterol. 2015, 21, 10956-10981. [CrossRef] [PubMed]

64. Zhang, H.; Bai, M.; Deng, T.; Liu, R.; Wang, X.; Qu, Y.; Duan, J.; Zhang, L.; Ning, T.; Ge, S.; et al. Cell-derived microvesicles mediate the delivery of miR-29a/c to suppress angiogenesis in gastric carcinoma. Cancer Lett. 2016, 375, 331-339. [CrossRef] [PubMed]

65. Liu, H.T.; Xing, A.Y.; Chen, X.; Ma, R.R.; Wang, Y.W.; Shi, D.B.; Zhang, H.; Li, P.; Chen, H.F.; Li, Y.H.; et al. MicroRNA-27b, microRNA-101 and microRNA-128 inhibit angiogenesis by down-regulating vascular endothelial growth factor $C$ expression in gastric cancers. Oncotarget 2015, 6, 37458-37470. [CrossRef] [PubMed]

66. Mei, B.; Chen, J.; Yang, N.; Peng, Y. The regulatory mechanism and biological significance of the Snail-miR590-VEGFR-NRP1 axis in the angiogenesis, growth and metastasis of gastric cancer. Cell Death Dis. 2020, 11, 241. [CrossRef]

67. Zhang, S.; Zhang, R.; Xu, R.; Shang, J.; He, H.; Yang, Q. MicroRNA-574-5p in gastric cancer cells promotes angiogenesis by targeting protein tyrosine phosphatase non-receptor type 3 (PTPN3). Gene 2020, 733, 144383. [CrossRef]

68. Seo, A.N.; Jung, Y.; Jang, H.; Lee, E.; Bae, H.I.; Son, T.; Kwon, O.; Chung, H.Y.; Yu, W.; Lee, Y.M. Clinical significance and prognostic role of hypoxia-induced microRNA 382 in gastric adenocarcinoma. PLoS ONE 2019, 14, e0223608. [CrossRef]

69. Si, Y.; Zhang, H.; Ning, T.; Bai, M.; Wang, Y.; Yang, H.; Wang, X.; Li, J.; Ying, G.; Ba, Y. miR-26a/b Inhibit Tumor Growth and Angiogenesis by Targeting the HGF-VEGF Axis in Gastric Carcinoma. Cell Physiol. Biochem. 2017, 42, 1670-1683. [CrossRef] 
70. Du, J.; Liang, Y.; Li, J.; Zhao, J.M.; Wang, Z.N.; Lin, X.Y. Gastric Cancer Cell-Derived Exosomal microRNA-23a Promotes Angiogenesis by Targeting PTEN. Front. Oncol. 2020, 10, 326. [CrossRef]

71. Liu, S.; Tian, Y.; Zhu, C.; Yang, X.; Sun, Q. High miR-718 Suppresses Phosphatase and Tensin Homolog (PTEN) Expression and Correlates to Unfavorable Prognosis in Gastric Cancer. Med. Sci. Monit 2018, 24, 5840-5850. [CrossRef] [PubMed]

72. Deng, T.; Zhang, H.; Yang, H.; Wang, H.; Bai, M.; Sun, W.; Wang, X.; Si, Y.; Ning, T.; Zhang, L.; et al. Exosome miR-155 Derived from Gastric Carcinoma Promotes Angiogenesis by Targeting the c-MYB/VEGF Axis of Endothelial Cells. Mol. Ther. Nucleic Acids 2020, 19, 1449-1459. [CrossRef] [PubMed]

73. Zhou, Z.; Zhang, H.; Deng, T.; Ning, T.; Liu, R.; Liu, D.; Bai, M.; Ying, G.; Ba, Y. Exosomes Carrying MicroRNA-155 Target Forkhead Box O3 of Endothelial Cells and Promote Angiogenesis in Gastric Cancer. Mol. Ther. Oncolytics 2019, 15, $223-233$. [CrossRef]

74. Bai, M.; Li, J.; Yang, H.; Zhang, H.; Zhou, Z.; Deng, T.; Zhu, K.; Ning, T.; Fan, Q.; Ying, G.; et al. miR-135b Delivered by Gastric Tumor Exosomes Inhibits FOXO1 Expression in Endothelial Cells and Promotes Angiogenesis. Mol. Ther. 2019, 27, 1772-1783. [CrossRef] [PubMed]

75. Fan, B.; Shen, C.; Wu, M.; Zhao, J.; Guo, Q.; Luo, Y. miR-17-92 cluster is connected with disease progression and oxaliplatin/capecitabine chemotherapy efficacy in advanced gastric cancer patients: A preliminary study. Medicine 2018, 97 , e12007. [CrossRef] [PubMed]

76. Riquelme, I.; Tapia, O.; Leal, P.; Sandoval, A.; Varga, M.G.; Letelier, P.; Buchegger, K.; Bizama, C.; Espinoza, J.A.; Peek, R.M.; et al. miR-101-2, miR-125b-2 and miR-451a act as potential tumor suppressors in gastric cancer through regulation of the PI3K/AKT/mTOR pathway. Cell Oncol. 2016, 39, 23-33. [CrossRef]

77. Zhang, J.X.; Chen, Z.H.; Chen, D.L.; Tian, X.P.; Wang, C.Y.; Zhou, Z.W.; Gao, Y.; Xu, Y.; Chen, C.; Zheng, Z.S.; et al. LINC01410-miR532-NCF2-NF-kB feedback loop promotes gastric cancer angiogenesis and metastasis. Oncogene 2018, 37, 2660-2675. [CrossRef] [PubMed]

78. Zhang, X.; Tang, J.; Zhi, X.; Xie, K.; Wang, W.; Li, Z.; Zhu, Y.; Yang, L.; Xu, H.; Xu, Z. miR-874 functions as a tumor suppressor by inhibiting angiogenesis through STAT3/VEGF-A pathway in gastric cancer. Oncotarget 2015, 6, 1605-1617. [CrossRef]

79. Aoyagi, K.; Kouhuji, K.; Yano, S.; Miyagi, M.; Imaizumi, T.; Takeda, J.; Shirouzu, K. VEGF significance in peritoneal recurrence from gastric cancer. Gastric Cancer 2005, 8, 155-163. [CrossRef]

80. Fondevila, C.; Metges, J.P.; Fuster, J.; Grau, J.J.; Palacin, A.; Castells, A.; Volant, A.; Pera, M. p53 and VEGF expression are independent predictors of tumour recurrence and survival following curative resection of gastric cancer. Br. J. Cancer 2004, 90, 206-215. [CrossRef]

81. Wang, X.; Chen, X.; Fang, J.; Yang, C. Overexpression of both VEGF-A and VEGF-C in gastric cancer correlates with prognosis, and silencing of both is effective to inhibit cancer growth. Int. J. Clin. Exp. Pathol. 2013, 6, 586-597.

82. Alessandrini, L.; Manchi, M.; De Re, V.; Dolcetti, R.; Canzonieri, V. Proposed Molecular and miRNA Classification of Gastric Cancer. Int. J. Mol. Sci. 2018, 19, 1683. [CrossRef]

83. Fuchs, C.S.; Tabernero, J.; Tomasek, J.; Chau, I.; Melichar, B.; Safran, H.; Tehfe, M.A.; Filip, D.; Topuzov, E.; Schlittler, L.; et al. Biomarker analyses in REGARD gastric/GEJ carcinoma patients treated with VEGFR2-targeted antibody ramucirumab. Br. J. Cancer 2016, 115, 974-982. [CrossRef]

84. Van Cutsem, E.; Muro, K.; Cunningham, D.; Bodoky, G.; Sobrero, A.; Cascinu, S.; Ajani, J.; Oh, S.C.; Al-Batran, S.E.; Wainberg, Z.A.; et al. Biomarker analyses of second-line ramucirumab in patients with advanced gastric cancer from RAINBOW, a global, randomized, double-blind, phase 3 study. Eur. J. Cancer 2020, 127, 150-157. [CrossRef] [PubMed]

85. Refolo, M.G.; Lotesoriere, C.; Lolli, I.R.; Messa, C.; D'Alessandro, R. Molecular mechanisms of synergistic action of Ramucirumab and Paclitaxel in Gastric Cancers cell lines. Sci. Rep. 2020, 10, 7162. [CrossRef] [PubMed]

86. Masood, N.; Basharat, Z.; Khan, T.; Yasmin, A. Entangling Relation of Micro RNA-let7, miRNA-200 and miRNA-125 with Various Cancers. Pathol. Oncol. Res. 2017, 23, 707-715. [CrossRef]

87. Qadir, M.I.; Faheem, A. miRNA: A Diagnostic and Therapeutic Tool for Pancreatic Cancer. Crit. Rev. Eukaryot. Gene Expr. 2017, 27, 197-204. [CrossRef]

88. Wu, M.; Wang, G.; Tian, W.; Deng, Y.; Xu, Y. MiRNA-based Therapeutics for Lung Cancer. Curr. Pharm. Des. 2018, 23, 5989-5996. [CrossRef]

89. Link, A.; Kupcinskas, J. MicroRNAs as non-invasive diagnostic biomarkers for gastric cancer: Current insights and future perspectives. World J. Gastroenterol. 2018, 24, 3313-3329. [CrossRef]

90. Shin, V.Y.; Chu, K.M. MiRNA as potential biomarkers and therapeutic targets for gastric cancer. World J. Gastroenterol. 2014, 20, 10432-10439. [CrossRef]

91. Ye, G.; Pan, R.; Zhu, L.; Zhou, D. Circ_DCAF6 potentiates cell stemness and growth in breast cancer through GLI1-Hedgehog pathway. Exp. Mol. Pathol. 2020, 116, 104492. [CrossRef]

92. Nie, H.; Xie, X.; Zhang, D.; Zhou, Y.; Li, B.; Li, F.; Li, F.; Cheng, Y.; Mei, H.; Meng, H.; et al. Use of lung-specific exosomes for miRNA-126 delivery in non-small cell lung cancer. Nanoscale 2020, 12, 877-887. [CrossRef]

93. Sabry, D.; El-Deek, S.E.M.; Maher, M.; El-Baz, M.A.H.; El-Bader, H.M.; Amer, E.; Hassan, E.A.; Fathy, W.; El-Deek, H.E.M. Role of miRNA-210, miRNA-21 and miRNA-126 as diagnostic biomarkers in colorectal carcinoma: Impact of HIF-1alpha-VEGF signaling pathway. Mol. Cell Biochem. 2019, 454, 177-189. [CrossRef] 
94. Alhasan, L. MiR-126 Modulates Angiogenesis in Breast Cancer by Targeting VEGF-A -mRNA. Asian Pac. J. Cancer Prev. 2019, 20, 193-197. [CrossRef]

95. Chen, S.W.; Lu, H.P.; Chen, G.; Yang, J.; Huang, W.Y.; Wang, X.M.; Huang, S.P.; Gao, L.; Liu, J.; Fu, Z.W.; et al. Downregulation of miRNA-126-3p is associated with progression of and poor prognosis for lung squamous cell carcinoma. FEBS Open Bio 2020, 10, 1624-1641. [CrossRef] [PubMed]

96. Hansen, T.F.; Carlsen, A.L.; Heegaard, N.H.; Sorensen, F.B.; Jakobsen, A. Changes in circulating microRNA-126 during treatment with chemotherapy and bevacizumab predicts treatment response in patients with metastatic colorectal cancer. Br. J. Cancer 2015, 112, 624-629. [CrossRef] [PubMed]

97. Switlik, W.Z.; Karbownik, M.S.; Suwalski, M.; Kozak, J.; Szemraj, J. Serum miR-210-3p as a Potential Noninvasive Biomarker of Lung Adenocarcinoma: A Preliminary Study. Genet. Test. Mol. Biomark. 2019, 23, 353-358. [CrossRef]

98. Wang, X.; Wang, T.; Chen, C.; Wu, Z.; Bai, P.; Li, S.; Chen, B.; Liu, R.; Zhang, K.; Li, W.; et al. Serum exosomal miR-210 as a potential biomarker for clear cell renal cell carcinoma. J. Cell Biochem. 2018, 120, 1492-1502. [CrossRef]

99. Cai, H.; Lin, L.; Cai, H.; Tang, M.; Wang, Z. Prognostic evaluation of microRNA-210 expression in pediatric osteosarcoma. Med. Oncol. 2013, 30, 499. [CrossRef]

100. Xu, X.; Zhu, S.; Tao, Z.; Ye, S. High circulating miR-18a, miR-20a, and miR-92a expression correlates with poor prognosis in patients with non-small cell lung cancer. Cancer Med. 2018, 7, 21-31. [CrossRef]

101. Brunet Vega, A.; Pericay, C.; Moya, I.; Ferrer, A.; Dotor, E.; Pisa, A.; Casalots, A.; Serra-Aracil, X.; Oliva, J.C.; Ruiz, A.; et al. microRNA expression profile in stage III colorectal cancer: Circulating miR-18a and miR-29a as promising biomarkers. Oncol. Rep. 2013, 30, 320-326. [CrossRef] [PubMed]

102. Kral, J.; Korenkova, V.; Novosadova, V.; Langerova, L.; Schneiderova, M.; Liska, V.; Levy, M.; Veskrnova, V.; Spicak, J.; Opattova, A.; et al. Expression profile of miR-17/92 cluster is predictive of treatment response in rectal cancer. Carcinogenesis 2018, 39, 1359-1367. [CrossRef]

103. Zhang, N.; Zhang, P.P.; Huang, J.J.; Wang, Z.Y.; Zhang, Z.H.; Yuan, J.Z.; Ma, E.M.; Liu, X.; Bai, J. Reduced serum exosomal miR-874 expression predicts poor prognosis in colorectal cancer. Eur. Rev. Med. Pharmacol. Sci. 2020, 24, 664-672. [CrossRef]

104. Kesanakurti, D.; Maddirela, D.R.; Chittivelu, S.; Rao, J.S.; Chetty, C. Suppression of tumor cell invasiveness and in vivo tumor growth by microRNA-874 in non-small cell lung cancer. Biochem. Biophys. Res. Commun. 2013, 434, 627-633. [CrossRef] [PubMed]

105. Diao, J.; Su, X.; Cao, L.; Yang, Y.; Liu, Y. MicroRNA874 inhibits proliferation and invasion of pancreatic ductal adenocarcinoma cells by directly targeting paired box 6. Mol. Med. Rep. 2018, 18, 1188-1196. [CrossRef] [PubMed] 